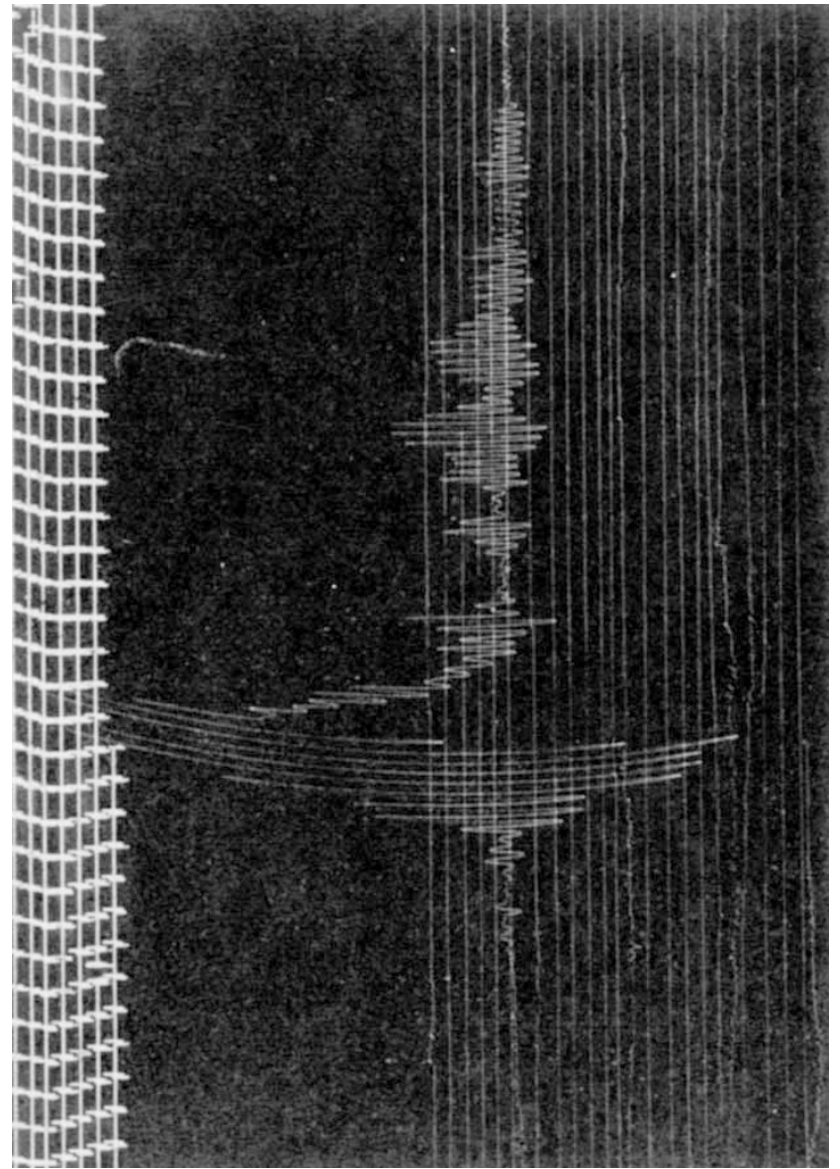

Cymograph record of the earthquake made on a horizontal pendulum seismograph at the Science Museum. Time scale (to left) is one minute. (Crown copyright, Science Museum, London.)

probably still in progress; studies of the folding of sediments suggest that Africa has moved some 70 kilometres towards Asia within the last few million years.

The young mountain ranges of Iran, the Zagros and the Elburz, date from the late Tertiary and are seismically active; mobile salt basins add to the instability of the area. There is little hope of applying to Iran the predictive measures developed for the San Andreas fault zone in California, which depend on a detailed historical knowledge of a well defined zone.

The loss of life in Iran is made greater by the build. ing methods in the mountain villages. Walls are built of mud or stone cemented with mud and the roofs commonly consist of timber with a mud coating. A fresh layer of mud is added each year to provide a waterproof covering and the cumulative weight makes the collapse of the roof in an earthquake particularly likely to be fatal.

For the survivors of the earthquake the tragedy is increased by the damage to the tunnel-wells or qanats. Qanats supply 75 per cent of the water used in Iran and many regions are entirely dependent on them. The qanats are gently sloping tunnels, sometimes 10 miles long, which carry water from water-bearing strata in the hills to the plains below. Their construction calls for considerable engineering skill, although practised with ancient and simple techniques, and they represent a sizable capital investment. A single qanat may cost nearly $\$ 400,000$ and take 20 years to build, though a recent estimate puts the average cost at about $\$ 10,000$ per kilometre.

\section{UNIVERSITY VACATIONS Plant Not Fully Utilized}

BERKELEY students are in revolt again and the French have been trying to run free summer universities, while in England another row is brewing over the proposed temporary closing of Hornsey College of Art by the Haringey Education Committee. But what of other British universities? How are they answering the increasing demand for university education and how efficiently are they utilizing the facilities they have? A Vice-Chancellors' committee under the chairmanship of Mr C. F. Carter of the University of Lancaster is studying the question of plant use during vacations, but the variety is so great that Mr Carter feels unable to generalize before all the evidence has been collected. A sampling of the attitudes of various universities would seem to bear this out-the University of Birmingham remains mostly closed throughout the sum. mer while maintenance work is carried out. No summer courses are held at the university and only the residence halls are used to any extent. At the University of Sussex, however, Mr C. de N. Hill, the deputy bursar in charge of conferences, feels that the university has such excellent facilities that they should be used to their fullest extent. Sussex is fairly busy with conferences all during the long vacation and especially during the Easter vacation, with between one and four usually in residence. Many are organized through one or more members of the faculty with particular interests. Others have no connexion with the university apart from its residential facilities and lecture halls.

At the University of Cambridge, many of the colleges encourage conferences as a means of raising money and thereby keeping fees down during the rest of the year. This is especially true of newer colleges such as Churchill, which also has the advantage of better facilities than many of the older colleges and is almost continuously busy from June to September. But the attitude of other Cambridge colleges ranges from King's, which accepts weekday conferences throughout all vacations but stresses that the students come first and that conferences must fit in with college life, to Magdalene, which accepts conferences in theory but few in practice. The bursar stressed that the governing body of Magdalene had consideration for the staff, which means that there is time only for one or two short conferences during the few weeks when there are no undergraduates in residence and the college kitchens are still open.

Few universities offer residential courses during the summer, although the extramural departments of both Cambridge and Oxford, especially Oxford, do hold summer schools. Oxford runs four courses, the best known of which is the International Graduate Summer School, a six week course for approximately 150 graduate students which this summer offered a survey course of seventeenth century England-its art, history and literature. The department also runs a three week English language course for 90-100 foreign teachers of English, a fortnight's course on Oxford for about twentyfive students and four week courses of about eighty 
students each on a variety of general subjects. All of these courses are residential and take over a college for accommodation; most of the teaching is done by the regular tutors from the extramural department with occasional lectures given by other Oxford University professors.

Obviously the options of a university or college must be limited by its facilities, but it seems clear that many institutions take too little interest in the full exploitation of their facilities.

\section{INSTRUMENTS \\ James Short's Telescopes}

The Royal Scottish Museum in Edinburgh has been holding an exhibition of the life and work of James Short, the Scottish telescope maker who died two hundred years ago. Short was born in Edinburgh in 1710, where he was educated at Heriot's Hospital, a school for the sons of burgesses, at the high school and the university, where he came under the influence of the professor of mathematics, Colin Maclaurin. It was at the university, in one of Maclaurin's rooms, that Short began to experiment with the construction of reflecting telescopes. He soon developed considerable skill and Maclaurin reported that the telescopes Short was producing were "by far the best of their lengths that have yet been executed".

During the 17th century, telescopes were of the refracting type and the quality of the image they formed was limited by spherical aberration and chromatic dispersion. To produce a satisfactory image,

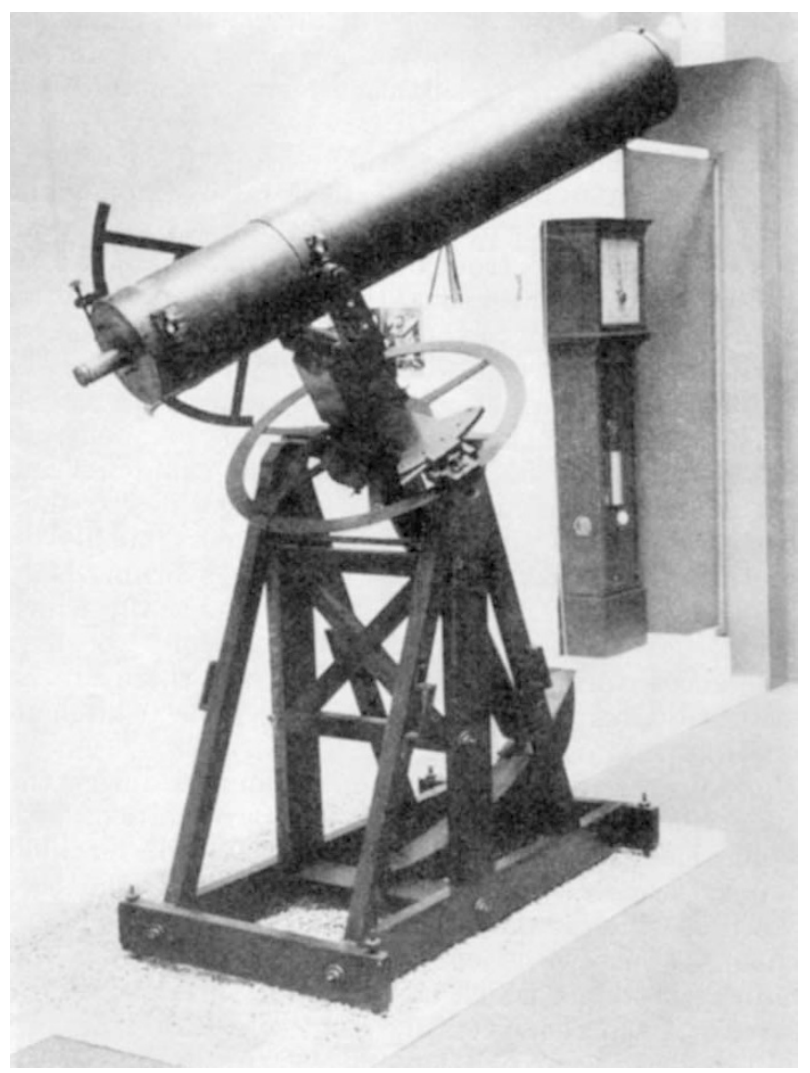

A 49 inch focus, $9 \frac{1}{4}$ inch aperture Gregorian reflector, made by James Short for the Paris Observatory, which lent it to the Royal Scortish Museum for the exhibition.
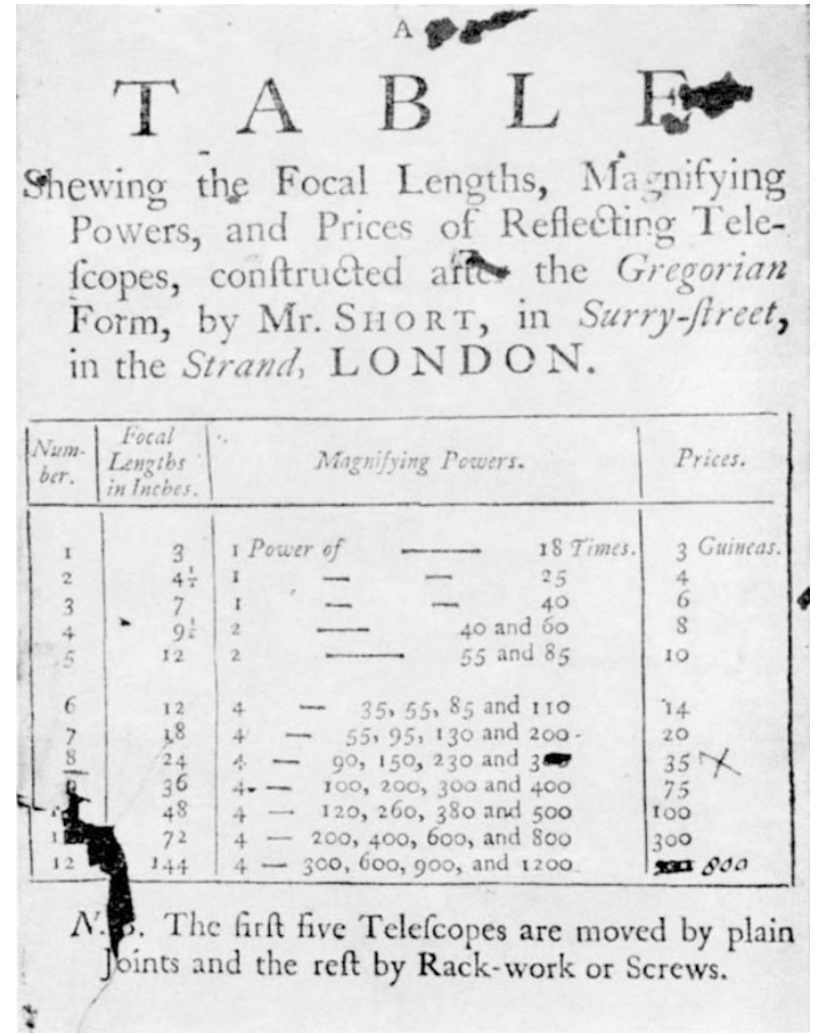

James Short's price list.

objectives had to have low curvatures, and hence long focal lengths, so that during the second half of the 17th century telescopes were inordinately lengthy. Sir Isaac Newton then realized that a telescope based on mirrors would be free from chromatic aberration, and in 1668 he built what was almost certainly the first reflector. James Gregory, the Scottish mathematician who held the chair of mathematics at Edinburgh University before Maclaurin, had earlier published a design for a reflecting telescope in which the image was viewed through a hole in the centre of the primary mirror, but the telescope was not built until after his death because opticians could not make mirrors of the required curvature. Following Newton's work, reflectors were preferred for many years-experiments with refractors had been discouraged by the mistaken assertion by Newton that it was impossible to correct a lens for chromatic aberration. It was at this stage in the history of telescopes that James Short was working, constructing the outstanding instruments of his time. Ten years before Short died, the London optician John Dolland made the first achromatic objective lens, but the technique of constructing reflectors had by then been brought to such a state of perfection that it was many years before refractors came back into favour among astronomers in the 19 th century. The absorption of light by glass objectives of large aperture led to the reflectors which are now the world's largest optical telescopes.

In 1737, Short was elected to the Royal Society and a year later he moved to London, where he made telescopes for the aristocrats who at that time were the patrons of astronomy. He made the first 12 foot focus reflector for the Duke of Marlborough at a cost of 600 guincas, and a 12 foot telescope which he sold 